Review

\title{
Meningiomas - insights into genetics and correlations with histological features
}

\author{
Adriana Grigorașs,1,2, Laura Rîșcanu ${ }^{1,2}$, Cornelia Amălinei ${ }^{1,2}$ \\ ${ }^{1}$ Department of Morphofunctional Sciences I, "Grigore T. Popa" University of Medicine and Pharmacy, \\ lasi, Romania, ${ }^{2}$ Department of Histopathology, Institute of Legal Medicine, lasi, Romania
}

\begin{abstract}
Meningiomas are the most common intracranial tumors. They occur more frequently in women and may be completely asymptomatic. According to the World Health Organization, the ability to invade and to develop recurrences represents the criterion which is used to designate three grades of meningiomas. In the last decade, advanced knowledges in genetics and molecular biology have improved our understanding of the clinical behavior of meningiomas. In addition to mutation or loss of NF2 gene, recurrent mutations of other genes, such as TERT, TRAF7, AKT1, AKT3, SMO, KLF4, SMARCE1, POLR2A, SUFU, BAP-1, PIK3CA, TSLC1, CDNK2A, $P T C H 1, T P 73, P T E N, N D R G 2, S 6 K$, and $C D N K 2 B$ have been identified within subsets of meningiomas. This review provides an overview and updates of the current knowledge of the genetics of meningioma in correlation with its histopathology. The insights into genetics and molecular profile of meningiomas may provide a valuable step towards developing new therapeutic approach for this type of intracranial tumor.
\end{abstract}

Keywords: meningioma; meningothelial cells; WHO grade; NF2; gene mutations

\section{Introduction}

Meningiomas are tumoral proliferations of meningothelial (arachnoid) cells, their location being as variable as the location of the component cells [1]. Since the first modern description of meningiomas by Cushing, at the beginning of the last century, the aim of numerous studies has been that of elaboration of specific criteria of aggressiveness in order to apply adequate therapeutic protocols [2, 3].

Currently, the scientists' interest regarding meningiomas is focused on defining the genetical profile of the tumor cells which is reflected in biological behavior, histologic type, location, clinical evolution, and prognosis. In this context, monosomy 22 and neurofibromatosis type 2

Received: January 2018; Accepted after review: March 2018; Published: March 2018.

${ }^{*}$ Corresponding author: Adriana Grigoras, MD, PhD, "Grigore T. Popa" University of Medicine and Pharmacy, Iași, 16 Universitatii Street, lasi, Romania. Email: a grigoras6600@yahoo.com
(NF2) diseases, harbouring inactivating mutations of NF2 gene, have been the first genetic anomalies correlated to meningiomas development [4]. These initial observations have been later completed by the identification of other genetic alterations, such as DAL-1, TRAF7, AKT1, KLF4, PTCH1, SMARCE1, BAP1, SMO, and PIK3CA mutations [4, 5]. These mutations have been identified in approximate $80 \%$ of sporadic meningiomas $[4,5]$.

The knowledge of intratumor molecular heterogeneity is also important considering the possible occurrence of tumor subclones, especially in malignant meningiomas $[6,7]$. Consequently, tumors would display therapy resistance and this may be addressed by alterative therapeutic tools, i.e. immunotherapy [6, 7].

All these accumulated data are opening new perspectives of targeted therapy and, subsequently, of improved prognosis, continuous research being needed for their clinical validation. 


\section{Epidemiology}

Meningiomas represent approximate 15\% of the total amount of cerebral tumors, being frequently located in the vicinity of venous sinuses, in the supratentorial region, along the medial area of parietal and frontal lobes, and in the sphenoid wing regions [8]. Less frequently, meningiomas may be located in the optic nerve sheath, cerebellopontine angle, choroid plexus, and spinal cord [8, 9]. Although, they are predominantly solitary lesions, multiple locations may be encountered in approximate $9 \%$ of patients [10].

Meningiomas represent about $37 \%$ of primary cerebral tumors in USA, with the standardised prevalence rate of $97.5 / 100,000$ individuals, as the most frequent primary intracranial adult tumor [11]. It is estimated that 27,100 newly diagnosed patients would be registered in 2017, in USA [12]. The necroptic diagnosis of meningiomas is not unusual, as the annual incidence of these reports is 3.9-5.3/100,000 cases [13].

These tumors are encountered most frequently in adults, with a peak incidence in the $6^{\text {th }}$ and $7^{\text {th }}$ decades. Meningiomas represent just $1.4 \%$ to $4 \%$ of intracranial tumors in children [14]. However, aggressive meningiomas have been also reported in children, most of them being identified within variable genetic syndromes [14].

Women are more frequently affected, with women: men ratio of approximate 1.7-2:1 [15]. There are some researchers reporting an even greater female-to-male ratio $(3.33: 1)$ for the posterior fossa meningiomas [16]. This feature has suggested the hypothesis of estroprogestative hormones involvement in the etiopathogeny of the disease, without reliable evidences to support this assertion up to now $[17,18]$

Next to genetic mutations, another contributor currently known to be associated to meningothelial tumor proliferation is represented by radiations to the head which have been demonstrated as facilitating factors of tumorigenesis [18, 19]. Commonly, the patients with a history of head radiation are developing more aggressive, atypical, or multifocal types of meningiomas [20].
Supplementary, studies performed in groups of children which had head radiation as therapeutic protocol for different types of cancer, have shown a direct correlation between high-dose radiotherapy and consequent meningiomas development [21, 22].

Although the hypothesis of dental radiographs involvement as an initiator of meningiomas formation has been launched, no direct correlation could be yet found between these two events [23-25].

\section{Historical perspective and morphology fundamentals}

The meningothelial tumors have been described in literature by different authors using variable terms, such as "epithelioma", or "dural endothelioma", or "angioendothelioma", or "fungus of the dura mater", or "fungoid tumors", or "psammoma", or "fibrosarcoma", or "meningeal fibroblastoma", or "meningoblastoma", or "mesothelioma of the meninges" [26-28].

The current term of "meningioma" was firstly used in 1922 by Harvey Cushing, for the characterization of a particular type of tumoral proliferation developed both in cerebral and in spinal cord locations [29].

However, the first documentation of this tumoral lesion had probably occurred several centuries before, in 1614, when Felix Plater, from University of Basel, registered in the autopsy of Sir Caspar Bonecurtius a relatively round tumor, with the size of a medium apple, exhibiting a firm consistence, covered by a membrane, entwined with veins, without a connection to the cerebral substance [28]. This is considered to be the first detailed gross description of a meningioma, in a patient showing progressive physical and mental decline $[28,30]$.

Although Plater is still considered the first person reporting a meningioma in the history of medicine, in fact this is not the first one registered in humans. This finding is based on the paleonthological studies performed on human fossils discovered in 1933, in a quarry near Steinheim an der Murr, in southern Germany, in which lesions compatible with meningioma had been found, dating for about 
365,000 years old [28, 31]. Accordingly, this is the first case of benign leptomeningeal lesion resembling meningioma reported in Homo erectus line [28, 31].

Few centuries later from the first gross description, Zanobi Pecchioli, Professor of Surgery at the University of Siena, had performed, in 1835, the first documented surgical intervention in literature that registered the successful resection of a meningioma [32].

Virchow is the first one to describe sandlike granulations in these meningothelial proliferations and had named them "psammoma body", in 1863 [33], while Bailey and Bucy had demonstrated their origin from the arachnoid cap cells [34].

\section{Gross and microscopic features}

The meningiomas are well shaped tumors, sometimes showing a lobulated pattern, with an increased up to firm consistency. They often infiltrate dura or dural sinuses and less frequently the cranial bones, overlying skin, or cerebral arteries walls [15]. The subjacent nervous tissue is compressed, generally without a direct cerebral invasion [4]. When meningiomas are developing along the sphenoid wing, they are presenting as flattened tumoral masses, rendering their name of "en plaque meningioma" [15]. The atypical variants of meningiomas are much larger and commonly show areas of necrosis. The microcystic subtype is particular by intratumoral or peritumoral cysts formation [35, 36].

Meningiomas may be also localized in the orbit, rarely having the optic nerves sheath as an origin $[15,37]$. They may be also located in the spinal cord (intradural extramedullary), mainly in its cervical thoracic region. Differently from the intracerebral location, spinal meningiomas may seldom infiltrate the adjacent bone tissue [15, 38].

Rare meningiomas locations may be: skin, nasal cavity, lung, or mediastinum, all of these may most probably represent the result of tumor proliferations developed in ectopic cellular areas exhibiting common structural and ultrastructural characteristics within meningothelial cells [39-42].
Although different in origin, meningiomas exhibit a multitude of microscopical features, a feature that has led to the necessity of their classification. In 1900, Engert proposed a first morphological classification into four types, as following: fibromatous, cellular, sarcomatous, and angiomatous [43]. This classification has been repeatedly modified both as number and nomenclature of meningiomas categories. Thus, according to Cushing and Bailey classification, realized in 1928, the meningiomas have been categorized into four types (meningothelial, fibroblastic, angioblastic, and osteoblastic), while Russell and Rubinstein, in 1971, have proposed a fivetype classification (syncytial, transitional, fibroblastic, angioblastic, and mixed type) [44].

Currently, according to 2007 WHO classification revised in 2016, meningiomas are classified in 15 morphological types which have been categorized into three groups of variable aggressivity, according to their microscopical characteristics and clinical evolution. Thus, grade I, grade II (atypical), and grade III (malignant) meningiomas have been described (Table 1) $[15,45,46]$. Meningothelial (Figure 1), fibrous (Figure 2), and transitional meningiomas are the most prevalent WHO types registered in medical practice [15].

Nonetheless, the revision of some morphological criteria has been performed in 2016, allowing the classification of benign arachnoid cell proliferations into atypical meningioma type. Subsequently, nowadays, all meningiomas associated with the invasion of the cerebral nervous tissue are categorized as atypical meningiomas. The rationale of the implementation of this criterion of classification has been supported by clinical observations showing that patients diagnosed with grade I meningiomas associated with the infiltration of the subjacent cerebral nervous tissue showed the same risk of local tumor relapse and of mortality as those registered in grade II WHO meningiomas $[45,46]$.

Another aggressivity criterion for all types of meningiomas is the mitotic count. Accordingly, based on the same WHO classification, 4-19 mitoses/10 microscopic high-power fields (HPF) represents a criterion of increased tumor aggressivity for 
meningiomas and, as a consequence, they are currently listed as atypical meningiomas.

Moreover, the diagnosis of atypical meningioma has to be supported by the association of three to five of the following morphological criteria: highly cellular tumors, with groups of small cells, exhibiting high nuclear: cytoplasmic ratio and conspicuous nucleoli, disposition into sheets, by changing the usual whorled pattern, along with tumor necrosis [45, 46]. Accordingly, meningiomas exhibiting less than 4 mitoses/10 HPF or maximum two of the previous morphological traits are categorized as grade I meningiomas [47]. If there is a loss of epithelial membrane antigen (EMA) expression, along with an increase in mitoses number, reaching more than 20 mitoses/10 HPF, meningiomas are regarded as Grade III [45, 46].

The microscopical features of the tumor cells are variable, as they may appear as clusters of cells without evident cell membranes, arranged in tight groups, in meningothelial type, or of elongated cells associated with an important collagen deposition in between them, in fibroblastic type of meningiomas [15]. In transitional meningioma, common features are noticed, exhibiting different proportions, characteristic both for syncytial and fibroblastic meningiomas, while numerous psammoma bodies are seen in psammomatous meningioma (Figure 3) [15, 44]. In secretory meningioma subtype, PAS-positive eosinophilic secretions, known as pseudopsammoma bodies, are identified [15, 44].

Atypical meningiomas show a group of morphological criteria associated to their enhanced aggressivity, expressed by an increased cellularity, high mitotic index and prominent nucleoli. Anaplastic types of meningiomas are the most aggressive categories, showing morphological traits which may mimic a sarcoma or a high grade carcinoma, complementary morphological examinations being necessary for tumor origin confirmation [44].

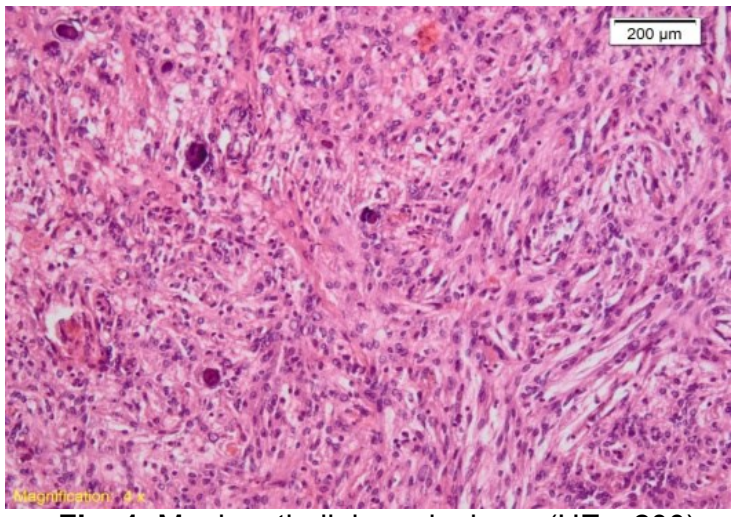

Fig. 1. Meningothelial meningioma (HE, x200)

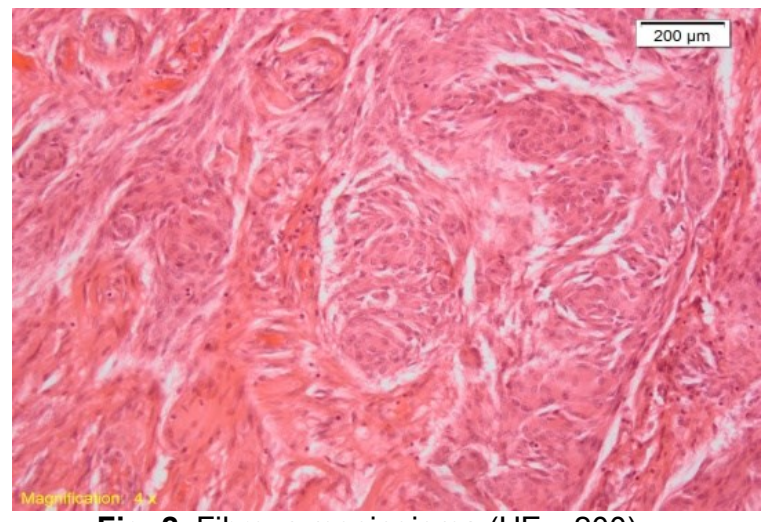

Fig. 2. Fibrous meningioma (HE, x200)

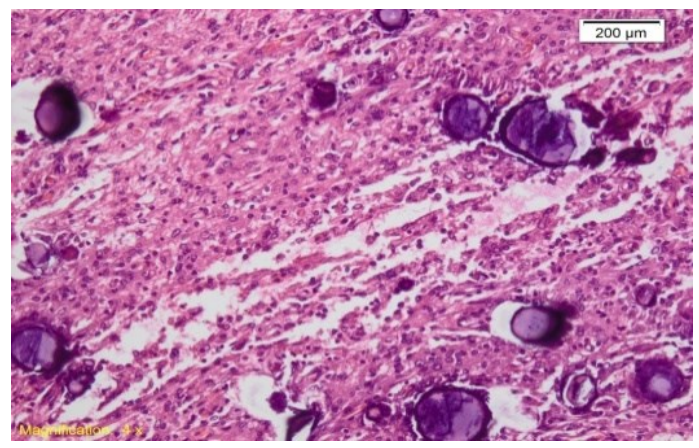

Fig. 3. Psammomatous meningioma (HE, x200) 
Table 1. WHO classification of meningiomas (adapted after Louis et al., 2016) [15]

\section{Meningioma WHO grade}

WHO grade I Meningioma

WHO grade II Meningioma

WHO grade III Meningioma

There are numerous evidences which support meningiomas origin from meningothelial cells of the arachnoid villi [3, 44]. Usually, in large venous sinuses, arachnoid extensions cross the entire thickness of the dura mater, slightly pushing the sinus endothelium inside the lumen. These prominences are exhibiting a connective tissue core covered by endothelium. They are forming the arachnoid villi which are directly connecting cerebrospinal fluid, from the arachnoid perforating the dura mater, to the sinuses lining endothelium [44]. The arachnoid villi represent the cerebrospinal resorption structures from the subarachnoid space to the venous system. With aging, arachnoid villi are increasing in size and may even become mineralized and, as a consequence, they become visible with naked eye, as granulations, known as Pacchionian granulation [48]. Electron microscopy studies along with molecular analyses have demonstrated that both arachnoid and tumor meningothelial cells have common ultrastructural features and similar matrix distribution of type I, III, and IV collagens, and laminin [49].

\section{Genetic mutations in meningiomas and the signaling pathways targeted}

Meningiomas are sporadic or developed within neurofibromatosis type 2 (NF2), an

\section{Histological type}

Meningothelial meningioma

Fibrous meningioma

Transitional meningioma

Psammomatous meningioma

Angiomatous meningioma

Microcystic meningioma

Secretory meningioma

Lymphoplasmacyte-rich meningioma

Metaplastic meningioma

Chordoid meningioma

Clear cell meningioma (intracranial)

Atypical meningioma

Papillary meningioma

Rabdoid meningioma

Anaplastic (malignant) meningioma

autosomal dominant genetic syndrome characterized by the mutation of NF2 gene, located on chromosome 22q12.2 [8,50]. Both NF2 allele mutations are inducing the loss of merlin (schwannomin), protein which is involved in the regulation of leptomeningeal cells proliferation [8]. Both NF2 alleles inactivation has been the first genetic defect described in patients diagnosed with this type of cerebral tumor [8]. NF2 gene is strongly expressed in embryonic stage, while it is mainly expressed in meningeal and Schwann cells, in lens and nerves, in adults [50].

Merlin protein is part of 4.1 protein family, with homologies with other proteins, such as ezrin, radixin, and moesin [8]. Merlin is located underneath the cell membrane and acts in the regulatory mechanism of cell membranecytoskeleton interaction, by mediating the cell membrane adherence to Actin filaments, in Sodium ions transport, in motility, and in intercellular contact $[51,52]$. Another function is that of tumor suppressor, by prevention of proliferation and uncontrolled growth of arachnoid, by inhibiting CUL4A-RBX1-DDB1VprBP/DCAF1 E3 ubiquitin-protein ligase complex [53].

Merlin inactivation has been registered in up to $70 \%$ of meningiomas, a feature constantly identified in meningothelial rather than in fibroblastic tumor type [54, 55]. Additionally, NF2 gene mutations along with a 
reduced merlin expression are correlated with increased Yes-associated protein (YAP) which is involved in the regulation of the arachnoid cells proliferation rate $[50,52]$.

Not only NF2 gene mutations are reported in literature (Table 2), but also other genetic anomalies responsible for different protein expression associated to meningiomas [52]. Specifically, loss of 4.1B (DAL-1) protein expression, as a result of $D A L-1$ gene mutation, on chromosome 18p11.32, is inducing the perturbation of the arachnoid control of cellular proliferation [56]. The later finding is supported by studies showing that approximate $50 \%$ of benign meningiomas harbor multiple genetic mutations involving TSC1 or both NF2 and DAL-1 gene [52, 56, 57].

Moreover, complex molecular analyses have revealed that an important percentage of meningiomas (30-85\%) have intercellular adhesion and motility perturbations associated not to $D A L-1$ but to TSLC-1 gene. The latter is normally codifying a protein that mediates cell membrane adhesion to the cytoskeleton Actin, acting via DAL-1 protein $[50,52,56]$.

Recent studies have revealed that the meningothelial tumor aggressivity is based on a multitude of genetic mutations registered in a list which has new members continuously added [3]. The analysis of this list reveals that associated mutations of cellular cycle, such as CDKN2A and CDKN2B, with mutations of genes located on chromosome 9, have been rarely detected in atypical type and more constantly in malignant types of meningiomas [15]. Moreover, CDNK2A mutations are associated with low patients' survival rate [2, $15,58]$.
Other genetic mutations have been recently registered in about $40 \%$ of sporadic non-NF2-mutant meningiomas, involving intercellular communication regulators, i.e. $A K T 1$ or of cellular growth and proliferation, such as $A K T 3$ and PIK3CA, transcriptional regulators, such as STAT3, POLR2A, and $G L 1$, cellular apoptosis coordinators, including arachnoid location, such as TRAF7, c-fos, or $b c l-2$, Hedgehog pathway regulating adult stem cells, involved in maintenance and regeneration of adult tissues, such as SMO and SUFU, cellular motility coordinators, i.e. TERT, and tumor suppressors, such as KLF4 and BAP1 (Table 2) [59-66].

These mutations are associated with morphological characteristics and with local aggressiveness, leading to the idea of a correlation between the spectrum of genetic mutations and their association with morphological type, along with therapy and evolution characteristics. In this regard, an almost exclusive association has been noticed between KLF4 gene mutations with secretory meningioma phenotype, while TRAF7 mutations are more frequently registered in non-secretory meningioma variants [67]. Moreover, TRAF7/AKT1 and SMO mutations are correlated to particular locations, as corresponding meningiomas have been identified in anterior fossa, median middle fossa, or anterior calvarium [4]. Meningiomas associated to TRAF7/KLF4 mutations are most constantly formed in certain locations, such as median posterior, anterior, median and lateral middle fossae and comprised by cells exhibiting an evident secretory feature [4].

Table 2. Correlation between genes along with their codified proteins functions and mutations associated to different meningiomas grade

\begin{tabular}{|c|c|c|c|c|c|}
\hline Grade & Gene & Location & Synthesized protein & Protein function & References \\
\hline \multirow{6}{*}{$\begin{array}{l}\text { Grade I } \\
\text { Meningioma }\end{array}$} & NF2 & $22 q 12.2$ & merlin & tumor suppressor & {$[8,50]$} \\
\hline & YAP1 & 11q22.1 & YAP / YAP1 & $\begin{array}{l}\text { transcriptional regulator in } \\
\text { the Hippo signaling pathway }\end{array}$ & {$[50,52]$} \\
\hline & DAL-1 & $18 p 11.32$ & 4.1B (DAL-1) & cell motility and adhesion & $\begin{array}{l}{[4,5,52,56,} \\
57]\end{array}$ \\
\hline & TSC1 & $9 q 34.13$ & hamartin & $\begin{array}{l}\text { cell growth and size } \\
\text { regulation }\end{array}$ & {$[52,56,57]$} \\
\hline & TRAF7 & $16 p 13.3$ & E3 ubiquitin ligase TRAF7 & apoptosis inducer & {$[4,5,64,67]$} \\
\hline & POLR2A & $17 p 13.1$ & $\begin{array}{l}\text { RPB1 (DNA-directed RNA } \\
\text { polymerase II subunit RPB1) }\end{array}$ & transcriptional regulation & {$[60]$} \\
\hline
\end{tabular}




\begin{tabular}{|c|c|c|c|c|c|}
\hline & TSLC-1 & $11 q 23.3$ & cell adhesion molecule 1 & $\begin{array}{l}\text { mediates intercellular } \\
\text { adhesion in a } \mathrm{Ca}(2+)- \\
\text { independent manner }\end{array}$ & {$[50,52,56]$} \\
\hline \multirow{11}{*}{$\begin{array}{l}\text { Grade II } \\
\text { Meningioma }\end{array}$} & TP73 & $1 \mathrm{p} 36.3$ & p73 & apoptosis inducer & [68-70] \\
\hline & PTEN & 10p23.3 & $\begin{array}{l}\text { phosphatidylinositol-3, 4,5- } \\
\text { trisphosphate 3-phosphate }\end{array}$ & tumor suppressor & [69] \\
\hline & AKT1 & $14 q 32.32$ & AKT1 kinase & intercellular communication & {$[4,5,63,64]$} \\
\hline & c-fos & $14 q 24.3$ & c-fos & transcription factor & [59-66] \\
\hline & $\mathrm{bcl}-2$ & $18 q 21.33$ & $\mathrm{Bcl}-2$ & apoptosis regulator & [59-66] \\
\hline & PTCH1 & $9 q 22.3$ & patched protein & Hedgehog pathway receptor & {$[4,5,70]$} \\
\hline & GLI1 & $12 q 13.3$ & Zinc finger proteins & transcription factor & {$[59-66]$} \\
\hline & STAT3 & $17 q 21.2$ & STAT3 protein & transcription factor & [59-66] \\
\hline & CDNK2A & $9 p 21.3$ & p16 & $\begin{array}{l}\text { tumor suppressor, cell cycle } \\
\text { progression (G1/S phase) }\end{array}$ & {$[2,15,58]$} \\
\hline & CDNK2B & $9 p 21.3$ & p15 & $\begin{array}{l}\text { tumor suppressor, cell cycle } \\
\text { progression (G1/S phase) }\end{array}$ & [15] \\
\hline & TERT & $5 p 15.33$ & hTERT & $\begin{array}{l}\text { immortalization of cancer } \\
\text { cells }\end{array}$ & [61] \\
\hline \multirow{17}{*}{$\begin{array}{l}\text { Grade III } \\
\text { Meningioma }\end{array}$} & TP73 & $1 \mathrm{p} 36.3$ & p73 & apoptosis inducer & [68-70] \\
\hline & PTEN & $10 p 23.3$ & $\begin{array}{l}\text { phosphatidylinositol-3, } 4,5- \\
\text { trisphosphate } 3-\text { phosphate }\end{array}$ & tumor suppressor & [69] \\
\hline & SUFU & $10 q 24$ & sufu & $\begin{array}{l}\text { negative regulator in } \\
\text { Hedgehog pathway }\end{array}$ & {$[66,70]$} \\
\hline & CDNK2A & $9 p 21.3$ & p16 & $\begin{array}{l}\text { tumor suppressor, cell cycle } \\
\text { progression (G1/S phase) }\end{array}$ & {$[2,15,58]$} \\
\hline & CDNK2B & $9 p 21.3$ & p15 & $\begin{array}{l}\text { tumor suppressor, cell cycle } \\
\text { progression (G1/S phase) }\end{array}$ & [15] \\
\hline & AKT1 & $14 q 32.32$ & AKT1 kinase & intercellular communication & {$[4,5,63,64]$} \\
\hline & bcl-2 & $18 q 21.33$ & Bcl-2 & apoptosis regulator & {$[59-66]$} \\
\hline & SMO & $7 q 32.1$ & smoothened GPCR & $\begin{array}{l}\text { cell localization (Hedgehog } \\
\text { pathway) }\end{array}$ & {$[4,5,63,64]$} \\
\hline & PTCH1 & $9 q 22.3$ & patched protein & Hedgehog pathway receptor & {$[4,5,70]$} \\
\hline & S6K & $17 q 23.1$ & S6 kinase & $\begin{array}{l}\text { cell growth, motility, and } \\
\text { adhesion }\end{array}$ & [71] \\
\hline & NDRG2 & $14 q 11.2$ & NDRG2 & tumor suppressor & [68] \\
\hline & PIK3CA & $3 q 26.32$ & p110 alpha $(p 110 \alpha)$ & $\begin{array}{l}\text { cell growth and division } \\
\text { (proliferation) }\end{array}$ & {$[4,5,65]$} \\
\hline & TERT & $5 p 15.33$ & hTERT & $\begin{array}{l}\text { immortalization of cancer } \\
\text { cells }\end{array}$ & [61] \\
\hline & KLF4 & $9 q 31.2$ & Kruppel-like factor 4 & tumor suppressor & $\begin{array}{l}{[4,5,62,64,} \\
67,74-76]\end{array}$ \\
\hline & $\begin{array}{l}\text { SMARCE } \\
1\end{array}$ & $17 q 21.2$ & SMARCE1 & $\begin{array}{l}\text { regulation of growth, } \\
\text { division, and maturation } \\
\text { (differentiation) of cells }\end{array}$ & $\begin{array}{l}{[3,4,5,72,} \\
73]\end{array}$ \\
\hline & BAP1 & $3 p 21.1$ & BAP1 & tumor suppressor & {$[4,5,59]$} \\
\hline & AKT3 & $14 q 43.44$ & AK3 kinase & $\begin{array}{l}\text { proliferation, cell survival, } \\
\text { growth, and angiogenesis }\end{array}$ & {$[66]$} \\
\hline
\end{tabular}

In grade II and III meningiomas other mutations have been registered, such as TP73, a regulator of apoptosis, PTEN and NDRG2 gene, as tumor suppressors, including the cerebral location, PTCH1 genes, Hedgehog pathway receptor [68, 69, 70], and S6K gene, located on 17q23.1 chromosome, codifying a protein which coordinates cellular growth, motility, and intercellular adhesion [71].

Clear cell meningiomas are more frequently associated with mutations of SMARCE1, a regulator of cellular growth and proliferation, including the arachnoid location, being different from angiomatous genotype which is characterized by multiple chromosomal polysomies, without NF2 mutations [3, 72, 73]. Supplementary, BAP1 mutations have been identified in aggressive meningiomas displaying a rhabdoid histomorphology [59].

However, an important percentage of meningiomas (up to $20 \%$ of sporadic types) lack any genetic mutations [5].

The radiation-induced meningiomas are different from spontaneous types, as the former frequently contain multiple chromosomal deletions involving 
chromosomes 1p, 6q, 9q, 10q, 14q, 17p, and $18 q$, being rather multifocal and associated with an aggressive tumor behavior [2, 44]. As NF2 gene mutations are extremely rare in these tumors, a different molecular mechanism seems to be involved in radiationinduced meningiomas.

Although documentations of genetic profile of meningiomas cells are available, the data are still incomplete, as much as intratumoral cellular heterogeneity is responsible for therapy resistance, along with loco-regional recurrences and metastases development in these tumors. This feature may be possibly related to meningeal cancer stem cells (CSCs) associated to tumor location. The current research focus is the isolation and the characterization of the molecular profile of these CSCs, as much as the arachnoid is made up of a heterogeneous cell population, containing meningothelial, fibroblastic and endothelial cells, but also some cells associated to arachnoid-dura interface. Up to now, results are supporting the possibility of such a CSC occurrence in meningeal tumors, expressing characteristic markers, such as CD133, c-Myc, KLF4, NANOG, nestin, OCT4, SOX2, and vimentin [74-76]. Furthermore, several pathways characteristically involved in stem-cell signaling, belonging to Fibroblast Growth Factor (FGF), Hedgehog, Transforming growth factor $\beta /$ Bone Morphogenetic Protein (TGF $\beta / B M P$ ), or Wnt are responsible for the maintenance of CSCs

\section{References}

1. Wiemels $J$, Wrensch $M$, Claus EB. Epidemiology and etiology of meningioma. $J$ Neurooncol 2010; 99(3):307-314.

2. Simon M, Boström JP, Hartmann C. Molecular genetics of meningiomas: from basic research to potential clinical applications. Neurosurgery 2007; 60(5):787-98.

3. Bi WL, Zhang $M, W u W W$, et al. Meningioma Genomics: Diagnostic, Prognostic, and Therapeutic Applications. Front Surg 2016; 3:40.

4. Yuzawa S, Nishihara H, Tanaka S. Genetic landscape of meningioma. Brain Tumor Pathol 2016; 33(4):237-247.

5. Bi $W L$, Abedalthagafi $M$, Horowitz $P$, et al. Genomic landscape of intracranial and pluripotent stem cells balanced values [77].

Nonetheless, the majority of issues regarding the meningeal stem cells are still waiting for answers, as their accurate characterization and identification might lead to a more efficient control of local tumor proliferation and a consequent prolonged therapeutic response.

\section{Conclusions}

The latest years' progresses regarding the genetic profile characterization of the tumor cells have led to the revival of the interest in meningiomas study. The results reported up to present have opened the possibility of a more appropriate correlation between genetic mutations type, microscopical features, and patients' management.

As the current management by chemotherapy and radiotherapy is not providing a complete cure, the discovery of new therapeutic approaches, by targeting CSCs, could open a new era, with the possibility of long term remission of these tumors.

\section{Conflict of interest/Funding Statement}

The authors have no conflict of interest to declare.

meningiomas. J Neurosurg 2016; 125(3):525535.

6. Rizvi NA, Hellmann MD, Snyder A, et al. Cancer immunology. Mutational landscape determines sensitivity to PD-1 blockade in nonsmall cell lung cancer. Science 2015; 348(6230):124-128.

7. Bi WL, Wu W, Santagata $S$, Reardon D, Dunn IF. Checkpoint inhibition in meningiomas. Immunotherapy 2016; 8(6):721-731.

8. Saraf S, McCarthy BJ, Villano JL. Update on meningiomas. Oncologist 2011; 16(11):16041613.

9. Buetow MP, Buetow PC, Smirniotopoulos JG. Typical, atypical, and misleading features in 
meningioma. Radiographics 1991; 11(6):10871106.

10. Lusins JO, Nakagawa $\mathrm{H}$. Multiple meningiomas evaluated by computed tomography. Neurosurgery 1981; 9(2):137-141.

11. Ostrom QT, Gittleman $H$, Farah $P$, et al. CBTRUS statistical report: primary brain and central nervous system tumors diagnosed in the United States in 2006-2010. Neuro Oncol 2013 15(Suppl. 2):ii1-56.

12. https://www.cancer.net/cancertypes/meningioma/statistics

13. Kuratsu J, Kochi M, Ushio $Y$. Incidence and clinical features of asymptomatic meningiomas. $J$ Neurosurg 2000; 92(5):766-770.

14. Goldstein RA, Jorden MA, Harsh IV. Meningiomas: Natural History, Diagnosis and Imaging. Philadelphia: Lippincott, Williams \& Wilkins, 2005

15. Louis DN, Ohgaki H, Wiestler OD, Cavenee WK. WHO Classification of Tumours of the Central Nervous System. $5^{\text {th }}$ edition. Lyon: IARC, 2016.

16. Dumitrescu GF, Indrei A, Husseini MEl, et al. Posterior fossa meningiomas: Correlation between site of origin and pathology. Rom Neurosurg 2010; 17:327-338.

17. Sanson MM, Cornu PP. Biology of meningiomas. Acta Neurochir 2000; 142(5):493-505.

18. Claus EB, Black $P M$, Bondy $M L$, et al. Exogenous hormone use and meningioma risk: what do we tell our patients? Cancer 2007; 110(3):471-476.

19. Bowers DC, Moskowitz CS, Chou JF, et al. Morbidity and mortality associated with meningioma after cranial radiotherapy: A report from the Childhood cancer survivor study. $J$ Clin Oncol 2017; 35(14):1570-1576.

20. Yousaf II, Byrnes DP, Choudhari KA. Meningiomas induced by high dose cranial irradiation. Br J Neurosurg 2003; 17(3):219225.

21. Neglia JP, Robison LL, Stovall MM, et al. New primary neoplasms of the central nervous system in survivors of childhood cancer: a report from the Childhood Cancer Survivor Study. J Natl Cancer Inst 2006; 98(21):15281537.

22. Meadows AT, Friedman DL, Neglia JP, et al. Second neoplasms in survivors of childhood cancer: findings from the Childhood Cancer Survivor Study cohort. J Clin Oncol 2009; 27(14):2356-2362.

23. Rodvall YY, Ahlbom AA, Pershagen GG, et al. Dental radiography after age 25 years, amalgam fillings and tumours of the central nervous system. Oral Oncol 1998; 34(4): 265269.

24. Longstreth WT, Phillips LE, Drangsholt MM, et al. Dental $X$-rays and the risk of intracranial meningioma: a population-based casecontrol study. Cancer 2004; 100(5):1026-1034.

25. Blettner MM, Schlehofer BB, Samkange-Zeeb FF, et al. Medical exposure to ionising radiation and the risk of brain tumours: Interphone study group, Germany. Eur J Cancer 2007; 43(13):1990-1998.

26. Ribbert MW. Uber das endotheliom der dura. Virchows Arch 1910; 200:141-151.

27. Schmidt M. Uber die pachionischen granulationen und ihr verhältnis zu den sarcomen und psammomen der dura mater. Virchows Arch 1902; 170:429-469.

28. Okonkwo DO, Laws Jr ER. Meningiomas: Historical Perspective. In: Lee J.H. (eds) Meningiomas. Springer, London, 2009, 3-10.

29. Cushing $\mathrm{H}$. The meningiomas (dural endotheliomas): their source and favored seats of origin (Cavendish Lecture). Brain 1922; 45:282-316.

30. al-Rodhan NR, Laws Jr ER. Meningioma: a historical study of the tumor and its surgical management. In: Al-Mefty O (ed). New York: Raven Press; 1991. 1-8.

31. Czarnetzki A, Schwaderer E, Pusch CM. Fossil record of meningioma. Lancet 2003; 362(9381):408.

32. Paterniti S. Meningiomas surgery in Italy in the nineteenth century: Historical review. Austin Neurosurg Open Access 2015; 2(2):1030.

33. Wang $\mathrm{H}$, Lanzino $\mathrm{G}$, Laws Jr ER. Meningioma: the soul of neurosurgery: historical review. Sem Neurosurg 2003; 14:163-168.

34. Bailey $P$, Bucy PC. The origin and nature of meningeal tumors. Am J Cancer 1931; 15:1554.

35. Bujok J, Bienioszek M. Microcystic variant of an intraosseous meningioma in the frontal area: a case report. Case Rep Neurol Med 2014; 2014:527267.

36. Matano $F$, Adachi $K$, Murai $Y$, et al. Microcystic meningioma with late-phase accumulation on thallium-201 single-photon emission computed tomography: case report. Neurol Med Chir (Tokyo) 2014; 54(8):686-689.

37. Tan LT, Stewart CM, Sheerin F, et al. Ectopic orbital meningioma: Fact or fiction? Orbit 2017; 36(3):144-146.

38. Bayoumi $A B$, Laviv $Y$, Karaali $C N$, et al. Spinal meningiomas: 61 cases with predictors of early postoperative surgical outcomes. J Neurosurg Sci 2017. doi: 10.23736/S0390-5616.17.041029 
39. Thompson LD, Gyure KA. Extracranial sinonasal tract meningiomas: a clinicopathologic study of 30 cases with a review of the literature. Am J Surg Pathol 2000; 24(5):640-650.

40. Suster $S$, Moran CA. Unusual manifestations of metastatic tumors to the lungs. Semin Diagn Pathol 1995; 12(2):193-206.

41. Ionescu D, Sasatomi E, Aldeeb D, et al. Pulmonary meningothelial-like nodules. A genotypic comparison with meningiomas. Am J Surg Pathol 2004; 28(2):207-214.

42. Burger PC, Scheithauer BW. Meningiomas. In: AFIP Atlas of Tumor Pathology: Tumors of the Central Nervous System. Washington, DC: American Registry of Pathology, 2007.

43. Cushing $\mathrm{H}$, Eisenhardt L. Meningiomas: Their classification, regional behaviour, life history and surgical end results. Springfield, 1938.

44. Pamir N, Black P. Meningiomas: A Comprehensive Text. Elsevier, Philadelphia, 2010.

45. Harter PN, Braun Y, Plate KH. Classification of meningiomas-advances and controversies. Chin Clin Oncol 2017; 6(Suppl 1):S2.

46. Sahm F, Reuss DE, Giannini C. WHO 2016 Classification: changes and advancements in the diagnosis of miscellaneous primary CNS tumours. Neuropathol Appl Neurobiol 2018; 44(2):163-171. doi: 10.1111/nan.12397.

47. Marciscano $A E$, Stemmer-Rachamimov $A O$, Niemierko A, et al. Benign meningiomas (WHO Grade I) with atypical histological features: correlation of histopathological features with clinical outcomes. J Neurosurg 2016; 124(1):106-114.

48. Kapoor KG, Katz SE, Grzybowski DM, Lubow M. Cerebrospinal fluid outflow: an evolving perspective. Brain Res Bull 2008; 77(6):327334.

49. Perry A, Gutmann DH, Reifenberger G. Molecular pathogenesis of meningiomas. $J$ Neuroncol 2004; 70(2):183-202.

50. Striedinger K, VandenBerg SR, Baia GS, et al. The neurofibromatosis 2 tumor suppressor gene product, merlin, regulates human meningioma cell growth by signaling through YAP. Neoplasia 2008; 10(11):1204-1212.

51. McClatchey Al, Giovannini M. Membrane organization and tumorigenesis - the NF2 tumor suppressor, Merlin. Genes Dev 2005; 19(19):2265-2277.

52. Miller R Jr, DeCandio ML, Dixon-Mah $Y$, et al. Molecular targets and treatment of meningioma. J Neurol Neurosurg 2014; 1(1) pii: 1000101.

53. Li W, You L, Cooper J, et al. Merlin/NF2 suppresses tumorigenesis by inhibiting the E3 ubiquitin ligase CRL4 (DCAF1) in the nucleus. Cell 2010; 140(4):477-490.

54. Robb VA, Li W, Gascard $P$, et al. Identification of a third Protein 4.1 tumor suppressor, Protein $4.1 \mathrm{R}$, in meningioma pathogenesis. Neurobiol Dis 2003; 13(3):191-202.

55. Pavelin S, Bečić K, Forempoher G, et al. The significance of immunohistochemical expression of Merlin, Ki-67, and p53 in meningiomas. Appl Immunohistochem Mol Morphol 2014; 22(1):46-49.

56. Dickinson PJ, Surace EI, Ca Leutenegger CM, et al. Expression of the tumor suppressor genes NF2, 4.1B, and TSLC1 in canine meningiomas. Vet Pathol 2009; 46(5):884-892.

57. Wang Z, Zhang J, Ye M, et al. Tumor suppressor role of protein 4.1B/DAL-1. Cell Mol Life Sci 2014; 71(24):4815-4830.

58. Pham MH, Zada G, Mosich GM, et al. Molecular genetics of meningiomas: a systematic review of the current literature and potential basis for future treatment paradigms. Neurosurg Focus 2011; 30(5):E7.

59. Shankar GM, Santagata S. BAP1 mutations in high-grade meningioma: implications for patient care. Neuro Oncol 2017; 19(11):1447-1456.

60. Clark VE, Harmancı AS, Bai H, et al. Recurrent somatic mutations in POLR2A define a distinct subset of meningiomas. Nat Genet 2016; 48(10):1253-1259.

61. Sahm F, Daniel Schrimpf, Adriana Olar, et al. TERT Promoter mutations and risk of recurrence in meningioma. J Natl Cancer Inst 2016; 108(5):djv377.

62. Tang $H$, Zhu $H$, Wang $X$, et al. KLF4 is a tumor suppressor in anaplastic meningioma stem-like cells and human meningiomas. J Mol Cell Biol 2017; 9(4):315-324.

63. Abedalthagafi $M, B i W L$, Aizer $A A$, et al. Oncogenic PI3K mutations are as common as AKT1 and SMO mutations in meningioma. Neuro Oncol 2016; 18(5):649-655.

64. Clark VE, Erson-Omay EZ, Serin A, et al. Genomic analysis of non-NF2 meningiomas reveals mutations in TRAF7, KLF4, AKT1, and SMO. Science 2013; 339(6123):1077-1080.

65. Zadeh G, Karimi S, Aldape KD. PIK3CA mutations in meningioma. Neuro Oncol 2016; 18(5):603-4.

66. Mei $Y, B i$ WL, Greenwald NF, et al. Genomic profile of human meningioma cell lines. PLoS One 2017; 12(5):e0178322.

67. Reuss DE, Piro RM, Jones DT, et al. Secretory meningiomas are defined by combined KLF4 $\mathrm{K} 409 \mathrm{Q}$ and TRAF7 mutations. Acta Neuropathol 2013; 125(3):351-358.

68. Skiriute D, Tamasauskas $S$, Asmoniene V, et al. Tumor grade-related NDRG2 gene 
expression in primary and recurrent intracranial meningiomas. J Neurooncol 2011; 102(1):8994.

69. Yakubov E, Ghoochani A, Buslei R, et al. Hidden association of Cowden syndrome, PTEN mutation and meningioma frequency. Oncoscience 2016; 3(5-6):149-155.

70. Kijima C, Miyashita T, Suzuki M, et al. Two cases of nevoid basal cell carcinoma syndrome associated with meningioma caused by a PTCH1 or SUFU germline mutation. Fam Cancer 2012; 11(4):565-570.

71. Surace EI, Lusis E, Haipek CA, Gutmann DH Functional significance of S6K overexpression in meningioma progression. Ann Neurol 2004; 56(2):295-298.

72. Smith MJ, Wallace AJ, Bennett $C$, et al. Germline SMARCE1 mutations predispose to both spinal and cranial clear cell meningiomas. J Pathol 2014; 234(4):436-40.

73. Abedalthagafi MS, Merrill $\mathrm{PH}, \mathrm{Bi} \mathrm{WL}$, et al. Angiomatous meningiomas have a distinct genetic profile with multiple chromosomal polysomies including polysomy of chromosome 5. Oncotarget 2014; 5(21):10596-10606.

74. Ciurea ME, Georgescu AM, Purcaru SO, et al. Cancer stem cells: Biological functions and therapeutically targeting. Int J Mol Sci 2014; 15(5):8169-8185.

75. Galani V, Alexiou GA, Miliaras G, et al. Expression of Stem Cell Marker Nestin and MicroRNA-21 in Meningiomas. Turk Neurosurg 2015; 25(4):574-577.

76. Shivapathasundram G, Wickremesekera AC, Tan ST, Itinteang T. Tumour stem cells in meningioma: A review. J Clin Neurosci 2018; 47:66-71. doi: 10.1016/j.jocn.2017.10.059.

77. Negah SS, Aligholi H, Khaksar Z, et al. Survival, proliferation, and migration of human meningioma stem-like cells in a nanopeptide scaffold. Iran J Basic Med Sci 2016; 19(12): 1271-1278. 